Tjalling C. Koopmans Research Institute

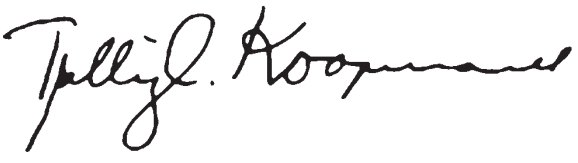

Discussion Paper Series nr: 05-28

\title{
Effects of Acquisitions on Product and Process Innovation and R\&D Performance
}

Elena Cefis

Stephanie Rosenkranz

Utz Weitzel 


\section{Tjalling C. Koopmans Research Institute Utrecht School of Economics Utrecht University}

Vredenburg 138

3511 BG Utrecht

The Netherlands

telephone $\quad+31302539800$

fax $\quad+31302537373$

website www.koopmansinstitute.uu.nl

The Tjalling C. Koopmans Institute is the research institute and research school of Utrecht School of Economics.

It was founded in 2003, and named after Professor Tjalling C. Koopmans, Dutch-born Nobel Prize laureate in economics of 1975.

In the discussion papers series the Koopmans Institute publishes results of ongoing research for early dissemination of research results, and to enhance discussion with colleagues.

Please send any comments and suggestions on the Koopmans institute, or this series to M.Damhuis@econ.uu.nl

ontwerp voorblad: WRIK Utrecht

\section{How to reach the authors \\ Please direct all correspondence to the first author.}

Elena Cefis

Stephanie Rosenkranz

Utz Weitzel

Utrecht University

Utrecht School of Economics

Vredenburg 138

3511 BG Utrecht

The Netherlands.

Phone: +31 (0)30- 2539856

Fax: $\quad+31(0) 30-2537373$

E-mail: e.cefis@econ.uu.nl

\section{s.Rosenkranz@econ.uu.nl}

u.weitzel@econ.uu.nl

Elena Cefis

University of Bergamo

Via Salvecchio 19

24129 Bergamo

Italy

Stephanie Rosenkranz

Center for Economic and Policy research

1611 Conneticut Ave.

NW. Suite 400

Washington DC, 20009

U.S.A. 


\title{
Effects of Acquisitions on Product and Process Innovation and R\&D Performance
}

\author{
Elena Cefisab \\ Stephanie Rosenkranz ${ }^{\text {ac }}$ \\ Utz Weitzela \\ ${ }^{a}$ Utrecht School of Economics \\ Utrecht University \\ ${ }^{\mathrm{b}}$ University of Bergamo \\ Italy \\ ${ }^{\mathrm{C}}$ CEPR \\ U.S.A.
}

June 2005

\begin{abstract}
Using a game theoretical model on firms' simultaneous investments in product and process innovation, we deduct and empirically test hypotheses on the optimal R\&D portfolio, investment, performance, and dynamic efficiency of R\&D for acquisitions and in independently competing firms. We use Community Innovation Survey data on Italian manufacturing firms. Theoretical and empirical results show that firms involved in acquisitions invest in different R\&D portfolios and invest at least as much in aggregate R\&D as independent firms. The empirical results do not support our hypothesis on dynamic efficiency since acquisitions lead to inferior R\&D performance.
\end{abstract}

Keywords: Mergers and Acquisitions; Innovation; Dynamic Efficiency; Cost Reduction; Product Differentiation

JEL classification: C72; L1; L13; O32

\section{Acknowledgements}

The authors wish to thank Rob Alessie, Karen Klomp, Hans Schenk, the participants at the ECIS seminar, Eindhoven University, March 2005, and at the 2nd IASTED International Conference on Alliances, Mergers and Acquisitions, MIT, Cambridge, Mass., 8-10 November 2004, for helpful comments and suggestions. This work has been accomplished with the cooperation of the Italian Statistical Office (ISTAT) and in particular of Andrea Mancini and Roberto Monducci, whose collaboration made this work possible. The research has been supported by the University of Bergamo (Elena Cefis, grant ex $60 \%$ n.60CEFI04, Dept. of Economics). 


\section{Introduction}

An intensively debated question in U.S. and European antitrust regulation is whether merger policy should move beyond its traditional static focus on market power (allocative efficiency) and production efficiency (X-efficiency) to incorporate innovation and dynamic efficiency. ${ }^{1}$ The body of literature in this area is still very limited, and most studies that analyse the effects of mergers and acquisitions on dynamic efficiency refer to innovative activities in general, regardless whether they are focused on processes or products. We argue that exactly this distinction between product and process innovation is important to fully understand the effects of acquisitions on dynamic efficiency. ${ }^{2}$ If product and process innovations have different externalities, changes in dynamic efficiency through an acquisition also depend on the magnitude of internalisation of these effects. An overpowering influence of only one dimension, either product or process innovation, could then determine aggregate innovative investment and performance. In this paper, we adapt an existing theoretical model and deduct testable hypotheses. We then empirically show that acquisitions do have different effects on product and process innovation with regard to R\&D investment, performance and dynamic efficiency.

Generally, we can distinguish between three strands of previous research in this area: (i) studies on product and process innovation in independently competing firms; (ii) studies on aggregate R\&D (i.e. without the distinction between product and process) and dynamic efficiency in acquisitions; and (iii) studies on product and process innovation in joint ventures.

1 For a comprehensive examination of the developing role of innovation in U.S. merger policy see Katz and Shelanski (2004).

${ }^{2}$ Throughout this paper we will use the term 'acquisitions' as a synonym for 'mergers and acquisitions' or any other kind of shared funding or equity-based interest with (shared) decision control or coordination. 
(i) From an individual firm's perspective, innovation strategies often focus either on process innovation or on product innovation. Michael Porter (1980) argues that a firm's strategic position within a broad-scope market is determined by one of two fundamental options: offer the lowest price or differentiate your products. Firms that attempt to pursue both strategies simultaneously, he claims, become 'stuck in the middle' between conflicting demand and cost parameters. His reasoning is based on the simple economic trade-off that higher quality or better performing products often cost more to develop and produce. Although Porter (1980) considers the two strategies of cost reduction and differentiation to be basically incompatible, several empirical studies provide evidence that the trade-off may not be as strong as originally suggested. Miller and Friesen (1986a, 1986b) make a strong case that a firm's advantage is rarely based entirely on costs or product differentiation and that both dimensions ought to be modelled and studied jointly. Such a less polarised world suggests that there exists an optimal level of investment in process $\mathrm{R} \& \mathrm{D}$ (cost reduction) and in product $\mathrm{R} \& \mathrm{D}$ (product differentiation). This notion is also widely accepted in innovation research, which stresses the general importance of an optimal mix in firms' R\&D portfolio. A prominent research path in industrial dynamics can be traced back to the seminal work of Abernathy and Utterback (1982), who introduced a technological life-cycle model of industries. It depicts the development of an industry from an initial 'fluid' stage, where market needs for a new technology are ill-defined and product innovation proliferates, to a final mature stage where there is a 'dominant design', and cost advantages as well as process innovation become the new critical factors to success. A number of theoretical and empirical studies usefully elaborate on this concept (Agarwal and Audretsch, 2001; Duranton, 2000; Klepper, 1996; Yin and Zuskovitch, 1998; Tushman and Anderson, 1986; Anderson and Tushman, 1990; Klepper and Graddy, 1990; and Suarez and Utterback, 1991), but without a specific focus on the strategic interdependence of firms' decisions or the role of acquisitions. 
(ii) When we depart from the distinction between product and process innovations, we find a growing debate whether acquisitions lead to higher or lower aggregate levels of innovation and dynamic efficiency. Unfortunately, despite the importance of the subject, the number of empirical studies is still very limited. This might be connected to the fact that, apart from industrial organisational models on joint ventures (see below), the theoretical literature largely remains mute on this issue. ${ }^{3}$ Some empirical studies on the financial and economic performance of acquisitions consider the consequences on firms' technological activities. However, aggregate results with regard to the influence of acquisitions on innovation levels turn out to be heterogeneous and difficult to compare: empirical analyses in industrial organization reach no consensus, but tentatively point towards a more positive relationship (Röller et al, 2001; also see Cohen and Levin, 1989; and Scherer, 1992, for useful reviews). Larger studies in the field of financial economics and corporate control are rather undecided, but tend to support the notion of a neutral or negative impact of acquisitions on R\&D (Hall, 1990, 1999; Ravenscraft and Scherer, 1987; Hitt et al, 1991, 1996; Blonigen and Taylor, 2000). In contrast to that, several smaller in depth studies on acquisitions and joint ventures convey a more positive outlook on innovative investment and performance (Gugler and Siebert, 2004; Ahuja and Katila, 2001; Cassiman et al, 2003; Adams and Marcu, 2004).

One reason why the empirical results are so mixed may be that many studies focus either on innovation input (e.g. R\&D spending) or on innovation performance (e.g. patents). Any conclusion for innovative behaviour in general then implicitly assumes a constant $\mathrm{R} \& \mathrm{D}$ efficiency. However, changes in static or dynamic efficiency - e.g. created through the elimination of R\&D duplication or scale/scope economies - can have opposing effects on the two variables: while $R \& D$ investment may be cut, joint $R \& D$ performance or output can still be unchanged or

\footnotetext{
${ }^{3}$ For a comprehensive survey see Cassiman et al (2003).
} 
even higher. ${ }^{4}$ For a thorough understanding of dynamic efficiency, we therefore have to take both sides into account. Another reason why empirical results are mixed may be that efficiency gains in acquisitions are often implicitly interpreted as cost synergies and thus expected to reduce investment in $\mathrm{R} \& \mathrm{D}$. However, the internalisation of technological spillover or other positive externalities increases marginal returns to innovation and therefore provides an incentive to invest more in R\&D after an acquisition, even under efficiency gains. As discussed below, we therefore include such externalities in our analysis.

(iii) A survey of the literature that studies the influence of acquisitions (or other forms of coordination) on product and process innovations quickly reveals that - next to a lack of empirical studies - most theoretical work is done in the field of industrial organisation. Initiated by the work of D'Aspremont and Jacquemin (1988) these studies mainly focus on the internalisation of positive or negative externalities through research joint ventures (RJVs) and their comparative static effects with regard to process and product $R \& D$ spending (de Bondt and Veugelers, 1991, de Bondt, 1997; Bonanno and Haworth, 1998). Process innovations can be seen as negative externalities, since lower prices force competitors to either 'wastefully' invest in corresponding cost reductions or accept lower profits due to the 'business stealing effect'. However, by forming an RJV or acquiring a firm, this negative externality can be internalised and avoided. Technological spillovers, on the other hand, can be seen as positive externalities, since competitors profit from the know-how of others without own investment. With acquisitions the returns lost to the innovator due to unprotected spillovers are (partially) captured and, depending on the magnitude of internalisation, lead to higher incentives to innovate. Most of the RJV literature focuses on spillovers when it addresses positive externalities. However, horizontal product differentiation can have the same effect when it reduces the substitutability of

\footnotetext{
${ }^{4}$ Especially when innovation measures are ill defined this can lead to some additional confusion whether terms like 'innovation' and 'innovation level' refer to R\&D investment/spending (input) or performance (output).
} 
competitors' products and increases consumers' willingness to pay. ${ }^{5}$ This leads to less direct competition and higher profits. An internalisation of horizontal differentiation captures the positive externalities of consumers' increased willingness to pay, which would otherwise be lost to competition. By modelling horizontal and vertical differentiation efforts in a strategic setting, Rosenkranz (2003) shows in a formal model that the formation of RJVs changes the optimal combination of product and process R\&D.

On the basis of past research we can thus assume for our analysis: provided that product and process $R \& D$ have different externalities, an acquisition should lead to an adjustment of the optimal mix of innovation investments since it internalises different degrees of positive and negative external effects. The analysis of these effects would not only explain changes in R\&D portfolios when firms coordinate formerly independent innovation decisions, but also illuminate an acquisition's impact on overall dynamic efficiency.

In this paper we adapt the model of Rosenkranz (2003) to our purposes and deduct testable hypotheses with which we can then empirically analyse the relative importance of process and product $\mathrm{R} \& \mathrm{D}$ in acquisitions and in independently competing firms. The model also allows us to formulate and test hypotheses about the aggregate investment, performance, and dynamic efficiency of acquisitions. In summary, the central questions addressed in our analysis are: do firms that are involved in acquisitions invest more in cost reduction or more in product

\footnotetext{
5 Much in line with Eswaran and Gallini (1996) this refers to horizontal innovations where no new product is automatically superior in the absolute sense. They simply have more distinctive characteristics, which generally increase consumers' valuation. An extreme example for such horizontal innovations in alliances is a multi purpose vehicle (MPV) dubbed 'Eurovan', which is produced by a joint venture of PSA Peugeot/Citroën and Fiat/Lancia. For each of the companies involved a technically identical van with slightly differentiated bodies is produced and then sold under the brand names Peugeot 806, Citroën Evasion, Fiat Ulysse, and Lancia Zeta. (These are the brand names used for the first generation of 'Eurovans' produced since 1994. For the second generation, which is produced since 2002, the names were partially changed to Peugeot 807, Citroën C8, Fiat Ulysse, and Lancia Phedra.) Other examples can be frequently found within automotive groups. In the Volkswagen group, for instance, Seat, Audi, Škoda, and Volkswagen build some of their cars on identical chassis platforms and with nearly identical technical characteristics, but these cars are nevertheless differentiated by interior and exterior design, branding and positioning.
} 
differentiation than independent firms? Do these firms generally invest more or less in product and process $R \& D$ than independent firms? Do acquisitions increase or decrease R\&D performance and dynamic efficiency?

For empirical testing we use cross sectional data from the first Italian Community Innovation Survey (CIS) on 18467 firms across all manufacturing industries and size groups (over 20 employees) which covers the period 1990 - 1992. We construct two samples, one with independent firms and one with firms that are members of a group. Based on the questionnaire of the CIS, membership in a group can be interpreted as a coordination of innovation strategies and decisions in acquisitions, mergers, joint ventures, cross holdings, or any other kind of shared funding or equity-based interest with (shared) decision control or coordination.

The empirical results support the propositions of the formal analysis in various aspects. Firms involved in acquisitions do invest differently in $\mathrm{R} \& \mathrm{D}$ than independent firms, i.e. more in product and less in process innovation. Furthermore, they invest at least an equal amount in aggregate R\&D. However, the empirical results also show that our hypotheses do not hold with regard to dynamic efficiency, since acquisitions lead to a comparatively worse R\&D performance.

The contribution of this paper to the current state of research is threefold: first, this study provides empirical evidence on the scarcely studied relationship between product and process innovation in combination with acquisitions. Second, this study provides theoretically motivated and empirically tested results about the effect of acquisitions on aggregate R\&D investment and performance. Third, in an area with relatively sparse theoretical and empirical literature, this analysis also contributes to the fundamental understanding of relevant forces that determine the overall level of dynamic efficiency in acquisitions. 
The paper is organised as follows: Section 2 presents the game theoretic model including the formulation of testable hypotheses. In Section 3 we describe the sample and the variables. The econometric analysis, its results and implications are presented in Section 4, followed by concluding remarks in Section 5.

\section{Formal Analysis and Hypotheses}

\subsection{The model}

We consider a duopolistic industry, consisting of two firms $i, j$ that produce quantities $x_{i}$ and $x_{j}$. The two firms operate under constant returns to scale. Firms' unit costs of production are given by $c_{i}$ and $c_{j}$ with $c_{i}, c_{j} \in[0, a]$, which can be chosen through $\mathrm{R} \& \mathrm{D}$ investment before the market opens. The product characteristics which determine the degree of product substitutability given by $\delta:=\delta_{i}+\delta_{j}$ can also be influenced by the firms $i, j$ through R\&D investment in $\delta_{i}$, and $\delta_{j}$ respectively, with $\delta_{i}, \delta_{j} \in\left[0, \frac{1}{2}\right]$.

The cost function for $\mathrm{R} \& \mathrm{D}$ is the same for both firms and is described by $K\left(c_{i}\right)+G\left(\delta_{i}\right)$ with $K^{\prime}<0, G^{\prime}<0$ and $K^{\prime \prime}>0, G^{\prime \prime}>0$. The higher the marginal costs and the lower product differentiation the lower is the needed research investment. We assume that there exists an initial level of costs $c^{o}$ with $K\left(c^{o}\right)=0$ for all $c_{i} \geq c^{o}$ and $\lim _{c_{i} \rightarrow c^{o}} K\left(c_{i}\right)=0$ and an initial level of product differentiation $\delta_{i}^{o} \leq \frac{1}{2}$ with $G\left(\delta_{i}^{o}\right)=0$ for all $\delta_{i} \geq \delta_{i}^{o}$ and $\lim _{\delta_{i} \rightarrow \delta_{i}^{o}} G\left(\delta_{i}\right)=0$. Further, (to guarantee interior solutions) we impose that $\lim _{c_{i} \rightarrow 0} K\left(c_{i}\right)=\infty$ as well as $\lim _{\delta_{i} \rightarrow 0} G\left(\delta_{i}\right)=\infty$, and we assume that no technological spillovers exist. 
Firms play a non-cooperative two-stage game under complete information. In the first stage, they decide on their marginal costs by investing in a research project generating a process innovation. Simultaneously, they decide on the optimal degree of product differentiation by investing in another research project generating a product innovation. In the second stage, firms choose quantities. Anticipating the outcome of the stage-two game as $x_{i}^{*}\left(c_{i}, c_{j}, \delta_{i}, \delta_{j}\right)$ and $x_{j}^{*}\left(c_{i}, c_{j}, \delta_{i}, \delta_{j}\right)$, firms choose optimal R\&D portfolios. Possible R\&D projects in such a portfolio are targeted at process innovation and at product innovation. Through the former they choose marginal costs of production and through the latter they choose a degree of product differentiation. Firms' strategies are $\left(c_{v}, \delta_{v}\right) \in R^{2}$, with $c_{v} \in\left[0, c^{o}\right]$ and $\delta_{v} \in\left[0, \delta_{i}^{o}\right]$ with $v=i, j$.

Now suppose that firms jointly decide on their R\&D activities after an acquisition. For simplicity we assume that they remain competitors in the second stage of the game. ${ }^{6}$ Assume that firms coordinate their strategies as to maximise joint profit but do not achieve efficiency gains because they utilise research technologies (both, for new products as well as processes) with decreasing returns. This rather unrealistic scenario is included in the analysis because it allows us to isolate the strategic effects of cooperative R\&D investment and the influence of efficiency gains.

Firms' joint profit is $\left(c_{i}, c_{j}, \delta_{i}, \delta_{j}\right) \in \arg \max _{c_{i}, c_{j}, \delta_{i} \delta_{j}}\left\{\Pi_{k}=\pi_{i}^{*}\left(c_{i}, \delta_{i}, c_{j}, \delta_{j}\right)+\pi_{j}^{*}\left(c_{i}, \delta_{i}, c_{j}, \delta_{j}\right)-K\left(c_{i}\right)-K\left(c_{j}\right)-G\left(\delta_{i}\right)-G\left(\delta_{j}\right)\right\}$.

Optimisation with respect to $c_{i}$ leads to the following first order condition, which characterises optimal investment into process innovation under coordinated $\mathrm{R} \& \mathrm{D}$ decisions, for $c_{i}^{*}=c_{j}^{*}=c_{k}^{*}$ :

\footnotetext{
${ }^{6}$ This is a common assumption in the IO literature when firms coordinate research strategies. A more complex analysis without such an assumption leads to not only qualitative identical, but altogether stronger results (see ...).
} 


$$
\frac{\partial \Pi_{k}}{\partial c_{i}}=\frac{\partial \Pi_{i}}{\partial c_{i}}+\frac{\partial \Pi_{j}}{\partial c_{i}}=0
$$

where $\Pi_{j_{c_{i}}}$ is the (negative) externality conferred by firm $i$ 's cost reduction on the profit of its rival $j$. Analogously, also the (positive) externality induced through product innovation by firm $i$ on the profit of firm $j$ is added to the competitive advantage externality that firm's R\&D effort has on its own profit through increasing the amount of differentiation of its competitor. Maximising joint profit with respect to the level of product differentiation $\delta_{i}$ yields the implicit function for optimal investment into product innovation in acquisitions, for $\delta_{i}^{*}=\delta_{j}^{*}=\delta_{k}^{*}$ :

$$
\frac{\partial \Pi_{k}}{\partial \delta_{i}}=\frac{\partial \Pi_{i}}{\partial \delta_{i}}+\frac{\partial \Pi_{j}}{\partial \delta_{i}}=0,
$$

Those externalities, positive or negative, are ignored when each firm chooses its $R \& D$ expenditure so as to maximise its own profit. They are internalised when the firms coordinate their R\&D strategies. This makes the individual maximisation problems equivalent to the joint maximisation problem that would be solved e.g. by a single decision maker for two firms that are combined through an acquisition.

To determine the effect of those strategic terms, the first-order conditions can be written as ${ }^{7}$

$$
\begin{gathered}
\pi_{i_{c_{i}}}-K^{\prime}+\beta \pi_{j_{c_{i}}}=0, \text { and } \\
\pi_{i_{\delta_{i}}}-G^{\prime}+\beta \pi_{j_{\delta_{i}}}=0,
\end{gathered}
$$

respectively, with $\beta=1$. By applying comparative statics with respect to $\beta$, the effects of adding these strategic terms to firms' first-order conditions of profit maximisation (and thus the effect of internalised externalities on firms' investment incentives) can be analysed. Taking all variables as functions of $\beta$, differentiation of (1) and (2) with respect to $\beta$ yields:

\footnotetext{
${ }^{7}$ Note that the equations represent the individual first order condition for $\beta=0$, while they represent the joint profit maximisation problem for $\beta=1$.
} 


$$
\begin{aligned}
& \left(\pi_{i_{c i c_{i}}}-K^{\prime \prime}+\beta \pi_{j_{c_{i} i_{i}}}\right) d c_{i}+\left(\pi_{i_{c_{i} \delta_{i}}}+\beta \pi_{\delta_{c_{i} \delta_{i}}}\right) d \delta_{i}+\pi_{j_{c_{i}}} d \beta=0, \\
& \left(\pi_{i_{\delta_{i} c_{i}}}+\beta \pi_{\delta_{\delta_{\delta_{i} c_{i}}}}\right) d c_{i}+\left(\pi_{i_{\delta_{\delta} \delta_{i}}}-G^{\prime \prime}+\beta \pi_{\delta_{\delta \delta_{i} \delta_{i}}}\right) d \delta_{i}+\pi_{j_{\delta_{i}}} d \beta=0 .
\end{aligned}
$$

Cramer's rule leads to:

$$
\begin{aligned}
& \operatorname{sign}\left(\frac{d c_{i}}{d \beta}\right)=\operatorname{sign}\left(-\left(\pi_{i_{\delta_{i \delta} \delta_{i}}}-G^{\prime \prime}+\beta \pi_{j_{\delta_{i \delta} \delta_{i}}}\right) \pi_{j_{c_{i}}}+\pi_{j_{\delta_{i}}}\left(\pi_{i_{c_{i} \delta_{i}}}+\beta \pi_{j_{c_{i} \delta_{i}}}\right)\right), \\
& \operatorname{sign}\left(\frac{d \delta_{i}}{d \beta}\right)=\operatorname{sign}\left(-\left(\pi_{i_{i c_{i}}}-K^{\prime \prime}+\beta \pi_{j_{c_{c i}}}\right) \pi_{j_{\delta_{i}}}+\pi_{j_{c_{i}}}\left(\pi_{i_{\delta_{i c_{i}}}}+\beta \pi_{j_{\delta_{i c_{i}}}}\right)\right) .
\end{aligned}
$$

The sign of the right-hand sides of both expressions is ambiguous if we do not make any further assumptions about the underlying demand functions. Obviously the slopes of the marginal R\&D cost functions (together with the sign of the externalities) determine whether R\&D investment increases or decreases. Now, assume negative externalities for process innovation and positive externalities for product innovation. This implies decreased investment in process innovation, e.g. $c_{i_{\beta}}>0$, if the right-hand side of the first expression is positive, which is true in case:

$$
G^{\prime \prime}>\left(\pi_{j_{c_{i}}}(1+\beta) \pi_{j_{\delta_{\delta} \delta_{i}}}-\pi_{j_{\delta_{i}}}(1+\beta) \pi_{i_{c_{i} \delta_{i}}}\right) /\left(\pi_{j_{c_{i}}}\right):=\hat{G}^{\prime \prime}
$$

Acquisitions increase investment in product innovation, e.g. $\delta_{i_{\beta}}<0$, whenever the right-hand side of the second expression is negative, or if:

$$
K^{\prime \prime}>\left(\pi_{j_{\delta_{i}}}(1+\beta) \pi_{i_{c i c i}}-\pi_{j_{c i}}(1+\beta) \pi_{j_{\delta_{i c i}}}\right) /\left(\pi_{j_{\delta_{i}}}\right):=\hat{K}^{\prime \prime}
$$

These conditions on the R\&D-cost functions can only be met if they allow for the existence of an equilibrium. To ensure that there exists an equilibrium for all values of $\beta$, the second-order condition has to be satisfied:

$$
G^{\prime \prime} \geq \pi_{i_{\delta_{i} \delta_{i}}}+\beta \pi_{j_{\delta_{i} \delta_{i}}}-\frac{\left(\pi_{i_{c_{i} \delta_{i}}}+\beta \pi_{j_{c_{i} \delta_{i}}}\right)^{2}}{\pi_{i_{c_{i} i_{i}}}+\beta \pi_{j_{c_{i} i_{i}}}-K^{\prime \prime}} .
$$


Substituting $\hat{K}^{\prime \prime}$ into this second-order condition of profit maximisation reveals that whenever $K^{\prime \prime}<\hat{K}^{\prime \prime}$ it is necessary for the equilibrium to exist that $G^{\prime \prime} \geq \hat{G}^{\prime \prime}$. Similarly, $G^{\prime \prime}<\hat{G}^{\prime \prime}$ requires that $K^{\prime \prime} \geq \hat{K}^{\prime \prime}$. This leads to the following proposition:

Proposition 1. A coordination of strategies through acquisitions induces firms to invest:

(i) more in product differentiation and less in process innovation if $K^{\prime \prime}>\hat{K}^{\prime \prime}$ and $G^{\prime \prime}>\hat{G}^{\prime \prime}$

(ii) more in process innovation and more in product innovation if $G^{\prime \prime}<\hat{G}^{\prime \prime}$,

(iii) or less in process innovation and less in product differentiation compared to the noncooperative equilibrium if $K^{\prime \prime}<\hat{K}^{\prime \prime}$.

It can definitely be excluded that firms invest more in process innovation, $c_{i_{\beta}}<0$, and less into product differentiation, $\delta_{i_{\beta}}>0$, when they coordinate their research strategies through an acquisition (as compared to the competitive equilibrium).

Proof: See the arguments above.

Keeping in mind that $\hat{K}^{\prime \prime}$ as well as $\hat{G}^{\prime \prime}$ are functions of R\&D spending one can simplify the interpretation as follows: if both marginal R\&D-cost functions are sufficiently steep (such that $K^{\prime \prime}>\hat{K}^{\prime \prime}$ and $G^{\prime \prime}>\hat{G}^{\prime \prime}$ ), acquisitions induce firms to invest more in product differentiation but less in process innovation. This finding corresponds to the general economic insight, that the internalisation of positive externalities should increase incentives to conduct R\&D while the opposite should hold for negative externalities. ${ }^{8}$ On the other hand, if marginal R\&D costs increase slowly for process innovation, that is $K^{\prime \prime}<\hat{K}^{\prime \prime}$, firms will invest less in both kinds of

\footnotetext{
${ }^{8}$ See DeBondt and Veugelers (1991) for a comprehensive discussion of the effects of investment externalities.
} 
innovation compared to firms with independent $\mathrm{R} \& \mathrm{D}$. If marginal costs for process innovation are low, negative externalities become strong for competing firms and the internalisation of those strong negative externalities over-compensates positive externalities. If the slope of marginal R\&D costs is low for product innovation, that is $G^{\prime \prime}<\hat{G}^{\prime \prime}$, firms invest more in both kinds of innovation. If firms can easily differentiate their products, the internalisation of positive externalities over-compensates negative externalities.

It is worthwhile to investigate whether firms also change the proportion of optimal R\&D investment as compared to $\mathrm{R} \& \mathrm{D}$ competition if they invest either more in both or less in both kinds of innovations. Consider the ratio of the first-order conditions of profit maximisation (1) and (2) given by:

$$
\frac{K^{\prime}}{G^{\prime}}=\frac{\pi_{i_{c_{i}}}+\beta \pi_{j_{c_{i}}}}{\pi_{i_{\delta_{i}}}+\beta \pi_{j_{\delta_{i}}}}
$$

and differentiate it with respect to $\beta$. Using (3) this yields:

$$
\frac{\partial \frac{K^{\prime}}{G}}{\partial \beta}=\frac{K^{\prime \prime}\left(\pi_{i_{\delta_{i}}}+\beta \pi_{j_{\delta_{i}}}\right)-G^{\prime \prime}\left(\pi_{i_{c_{i}}}+\beta \pi_{j_{c_{i}}}\right)}{\left(\pi_{i_{\delta_{i}}}+\beta \pi_{j_{\delta_{i}}}\right)^{2}}
$$

From this we can see that firms proportionately invest more into product innovation whenever

$$
K^{\prime \prime} \frac{\left(\pi_{i_{\delta_{i}}}+\beta \pi_{\delta_{\delta_{i}}}\right)}{\left(\pi_{i_{c_{i}}}+\beta \pi_{j_{c_{i}}}\right)}>G^{\prime \prime}
$$

Considering the conditions on the marginal R\&D-cost functions from the proposition, this condition is most likely satisfied whenever firms invest more into both types of innovation. For the case that firms invest less into both kinds of innovation it is more likely that they shift their innovations towards more process innovation. 


\subsection{Deduction of hypotheses}

Based on proposition 1 of the formal analysis we can now deduct testable hypothesis about (i) the optimal relation between product and process $R \& D$, (ii) the optimal level of $R \& D$ investment, and (iii) about R\&D performance and dynamic efficiency after an acquisition.

(i) With regard to the effects of acquisitions on the optimal relation between product and process R\&D, the formal analysis predicts two clearly observable changes: first, it predicts that the relationship never changes towards less product $R \& D$ and more process $R \& D$. Second, it predicts that there will be relatively more (less) investment in product (process) R\&D if the marginal costs for both types of innovation are above a critical value. In other words, firms should not be right at the 'beginning' of convex cost functions where R\&D is cheap and marginal costs are extremely small, neither for product nor process innovation.

According to research in industrial dynamics, discussed in the introduction, we would expect comparatively low marginal costs in product and process R\&D primarily in the early (or 'fluid') stages of a technological life cycle, where firms experiment with various first designs and production technologies. Since we will test the hypotheses with a broad sample of Italian data across all manufacturing industries and several stages of the life cycle, we expect the average firm to be neither in a very early (formative) nor very late (declining) technological stage. This implies that marginal costs for product and process $\mathrm{R} \& \mathrm{D}$ (and respective innovation decisions) have reached a certain critical level of 'non-trivial' impact, since the average cross sectional firm is bound to operate in a rather mature industry where both types of innovation are more or less equally developed. Hence, we can formulate the following hypothesis.

Hypothesis I (relative R\&D input): 
Firms that are involved in acquisitions invest, ceteris paribus, a larger (smaller) share of their total R\&D expenditures in new products (processes) than independently competing firms.

(ii) When we turn to the effect of acquisitions on the level of R\&D investment, the results of the formal model are more complex: in principle, low marginal costs for process (product) R\&D can lead to a decrease (increase) in aggregate $\mathrm{R} \& \mathrm{D}$ while at least moderate marginal costs for both types of R\&D can lead to offsetting counter effects and more or less unchanged aggregate investments. However, as the formal discussion of proposition 1 shows, acquisitions with a higher (lower) investment in product (process) $\mathrm{R} \& \mathrm{D}$ in relative terms are also likely to invest at a higher or at least equally high level in product, process and aggregate R\&D. Hence, if hypothesis I and its underlying assumptions are supported, the following hypotheses over the effects of acquisitions on R\&D investment can be formulated.

Hypothesis II (level of R※D input):

Firms that are involved in acquisitions invest at a higher or at least equally high level in product, process, and aggregate R\&D than independently competing firms, bolding other factors constant.

(iii) Under the ceteris paribus assumption of unchanged efficiency, the input-related hypotheses II would predict a similar output-related influence of acquisitions on the level of R\&D performance. However, since the model allows for an increase as well as a decrease in the level of R\&D performance this would not advance the analysis of dynamic efficiency in acquisitions. We therefore directly formulate the following hypotheses:

Hypothesis III.a (bigher R\&D efficiency):

Firms that are involved in acquisitions have, ceteribus paribus, a bigher efficiency in R $\omega D$ than independently competing firms. 
Hypothesis III.b (lower R\&D efficiency):

Firms that are involved in acquisitions have, ceteribus paribus, a lower efficiency in R\&D than independently competing firms.

\section{The Data and the Variables}

Our empirical analysis uses data drawn from the First Community Innovation Survey (CIS1) in Italy. The CIS is a comprehensive survey on innovation activities of firms covering European Union member States and European Union Candidate countries. Data are collected on a fouryearly basis and the first survey was held in 1993 on the innovative activities performed by firms during the previous three years, namely 1990-1992.

The CIS has been designed to acquire information on various aspects of the innovation process that takes place inside firms, like the sources of information and knowledge, the different types of innovation, the effects of innovation on firm's performances, etc. The statistical unit is the enterprise, as defined in the Council Regulation ${ }^{9}$ or as defined in the statistical Business Register of the country. This regulation defines the enterprise as "the smallest combination of legal units that is an organisational unit producing goods or services, which benefits from a certain degree of autonomy in decision making, especially for the allocation of its current resources", in other words, a company or a legally independent firm. ${ }^{10}$

\footnotetext{
${ }^{9}$ Council Regulation (EEC) No 696/93 of 15 March 1993, OJ N L76 of the 3 March ${ }^{10}$ The aims, the methodology, the definitions and the questionnaire used in innovation surveys are described in the OECD Oslo Manual (OECD, second edition from 1997 and third edition from 2005).
} 
The CIS data are collected both through census and/or sample surveys. CIS are based on stratified samples according to the industry classification (NACE) and the size (number of employees).

The size-classes are 3: 20-49 employees (small) (in some countries, and depending on the wave, the first class starts at 10 employees), 50-249 employees (medium-sized) and more than 250 employees (large). The industrial stratification is by NACE at the 2-digit level. The census has been used when the stratum size is too small for sampling (especially in countries with few large firms).

In a comparative analysis of innovative indicators Kleinknecht et al. $(1996,2002)$ show that the CIS indicators measure innovation input and output more comprehensively and more directly than earlier measures. Indeed, CIS data have lately became a fundamental source to analyze innovation at the firm-level (among others, see Cassiman and Veugelers, 2002; Mairesse and Mohnen, 2002; and Laursen and Salter, 2004 as recent contributions using CIS data)

The first Italian CIS had a rather high response rate of almost 65 per cent, considering that the majority of the countries had response rates between 41 and 56 per cent (Eurostat, 2003). Our sample is constituted by 18,467 firms across all manufacturing sectors and size classes. The data supply information on firms' innovative activities during the period 1990-92, while some variables (like total sales) concern only the year 1992.

The first Italian CIS is composed of 10 sections among which the first one requires general information of the firm and in particular whether the firm is member of a group. Whenever the answer is positive the firm is asked whether it is the headquarter of the group, and in the negative case whether the headquarter of the group is Italian or foreign. 
Out of 18,467 firms 3302 respondents (17.9\%) declared themselves member of a group. We consider them to be part of an equity-based coordination of innovation decisions and label them GROUP. ${ }^{11} 15165$ respondents $(82,1 \%)$ do not belong to any group. We consider them to be independently competing firms and label them INDEP. Table 1 describes the complete sample and the two sub-samples in more detail.

Table 1: Descriptive Statistics of Italian manufacturing firms in $1^{\text {st }} \mathrm{CIS}, 1992$

\begin{tabular}{|l|r|r|r|r|r|r|}
\cline { 2 - 7 } \multicolumn{1}{c|}{} & \multicolumn{2}{c|}{ Total sample } & \multicolumn{2}{c|}{ GROUP } & \multicolumn{2}{c|}{ INDEP } \\
\cline { 2 - 7 } \multicolumn{1}{c|}{} & $\begin{array}{c}\text { Total Sales } \\
\text { (in mil Lire) }\end{array}$ & employees & $\begin{array}{c}\text { total sales } \\
\text { (in mil Lire) }\end{array}$ & employees & $\begin{array}{c}\text { total sales } \\
\text { (in mil Lire) }\end{array}$ & employees \\
\hline $\mathrm{N}$ & 18467 & 18467 & 3302 & 3302 & 15165 & 15165 \\
\hline Mean & 29025 & 104 & 108828 & 326 & 11649 & 55 \\
\hline S.D. & 366421 & 859 & 858360 & 1998 & 37753 & 128 \\
\hline $25^{\text {th }}$ pctl & 3346 & 27 & 9364 & 43 & 2978 & 26 \\
\hline Median & 6733 & 37 & 22734 & 94 & 5593 & 34 \\
\hline $75^{\text {th }}$ pctl & 15708 & 71 & 60075 & 230 & 11455 & 55 \\
\hline
\end{tabular}

Not surprisingly, the average size of companies in GROUP and INDEP is noticeably different with regard to most moments. Firms belonging to groups (GROUP) have average sales that are almost 9.5 times larger than those of independent firms (INDEP) and the median is 4 times larger. Furthermore the mean of the number of employees in GROUP is 6 times larger and the median almost 3 times. In general, we can observe that the entire distributions of firms belonging to groups are shifted upward with respect to those of independent firms, regardless the proxy for size: total sales or number of employees.

Since the theoretical model gives predictions on the proportion between product and process innovation of $R \& D$ expenses and performances, firms with positive $R \& D$ expenses are our target population. Therefore, we select all firms with a positive R\&D budget. Table 2 describes this sub

\footnotetext{
11 As mentioned earlier, this definition can include acquisitions, mergers, joint ventures, cross holdings, or any other kind of shared funding or equity-based interest with (shared) decision control or coordination.
} 
sample of 3696 firms, split up into GROUP (coordinated innovation decisions) and INDEP (independent innovation decisions).

Table 2: Descriptive Statistics of Italian manufacturing firms with positive R\&D budget, 1992

\begin{tabular}{|l|r|r|r|r|}
\cline { 2 - 5 } \multicolumn{1}{c|}{} & \multicolumn{2}{c|}{ GROUP } & \multicolumn{2}{c|}{ INDEP } \\
\cline { 2 - 5 } \multicolumn{1}{c|}{} & $\begin{array}{c}\text { total sales } \\
\text { (in mil Lire) }\end{array}$ & employees & $\begin{array}{c}\text { total sales } \\
\text { (in mil Lire) }\end{array}$ & employees \\
\hline $\mathrm{N}$ & 1266 & 1266 & 2430 & 2430 \\
\hline Mean & 213387 & 606,06 & 19065 & 87,34 \\
\hline S.D. & 1374406 & 3176,12 & 36481 & 284,34 \\
\hline $25^{\text {th }}$ pctl & 15617 & 72 & 5100 & 30,00 \\
\hline Median & 41189 & 168,00 & 9719 & 46,50 \\
\hline $75^{\text {th }}$ pctl & 109892 & 435 & 20015 & 88 \\
\hline
\end{tabular}

The median (mean) of sales of all firms in GROUP is about 4 (9.5) times larger than the corresponding size in INDEP (see table 1) It is worth noting that the magnitude of this size difference persists in the sub sample of firms investing in R\&D: the median (mean) of sales of all firms in GROUP is about 4.2 (11.2) times larger than the corresponding size in INDEP (see table 2). As for the entire CIS sample, the entire distributions of firms belonging to groups are shifted upwards, regardless the proxy for size.

The Community Innovation Survey is professionally generated by several European National Statistical Offices and frequently used in diverse economic studies. However, for the purpose of our paper, a limitation of the data is that we cannot trace the exact date or modalities of the acquisition that led to the formation of a group. We therefore neither know the 'age' of the assumed externalities at work, nor the percentage of interest acquired in another firm.

Fortunately, although these details would give our analysis more substance, the formal model and deduction of hypotheses only require a differentiation between coordinated and independent decisions in innovation, regardless of formal corporate control or age of relation. Thus, the fact 
that respondents consider themselves to be a 'part of a group' indicates their willingness to coordinate their behaviour and in this sense fulfil our definition of an 'acquisition'.

\subsection{The variables}

Sections 6 and 8 of the first Italian CIS focus respectively on R\&D activities and on the effects on firm's performance of innovation activities. Data pertaining to these sections provide detailed measures of innovation inputs and outputs, which we use as such or partially transform. Cur empirical investigation focuses on investment, performance and efficiency variables. (variables (a), (b) and (c)) for which we choose to analyse the proxies reported below each variable in capital letter:

a) Investment variables (input-related):

TOT-IN: $\quad$ total R\&D expenses divided by total sales

PROD-IN: $\quad$ R\&D expenses devoted to product innovation divided by total sales

PROC-IN: $\quad$ R\&D expenses devoted to process innovation divided by total sales

PROD-REL-IN: $\quad$ R\&D expenses in product innovation as percentage of total R\&D expenses

PROC-REL-IN: $\quad$ R\&D expenses in process innovation as percentage of total R\&D expenses

(PROD-IN and PROC-IN complement to 100\% of total R\&D expenses)

b) Performance variables (output-related):

TOT-OUT: $\quad$ percentage of total sales realised with new products and processes

PROD-OUT: $\quad$ percentage of total sales realised with new products

PROC-OUT: $\quad$ percentage of total sales realised with new processes 
TOT-EFF:

PROD-EFF:

PROC-EFF:

Control variables:

SIZE:

GROUP_DUM:

IND_DUM:
TOT-OUT/TOT IN

PROD-OUT/PROD-IN

PROC-OUT/PROC-IN

Log of total sales in 1992 (in mil. Lire)

Dummy variable indicating whether a firm is 'part of a Group'

HQ_DUM: Dummy variable indicating whether the headquarter of the Group resides outside Italy

Industry dummies at 2 digit SIC level

\section{Empirical Results}

\subsection{Effect of acquisitions on $R \& D$ investment}

We initially perform a non-parametric analysis in order to test our hypothesis. Table 3 reports the descriptive statistics of the variables of interest, while Table 4 shows the results of different two sample tests, namely Levine's ${ }^{12}$ test for the equality of variance, the t-test for the equality of the means and the Kolgomorov-Smirnov ${ }^{13}$ test for the equality of the entire empirical distributions. Hypothesis I states that firms involved in acquisitions (GROUP) invest a larger (smaller) share of aggregate $R \& D$ in new products (new processes) than independent firms (INDEP). Table 3 reports that firms that are part of a group invest on average 4.7 percent more (less) of their total

\footnotetext{
${ }^{12}$ We perform the Levine's test for the equality of variance among the two sample distributions. According to the Levine's test results, we apply a t-test procedure to check whether the means of the two sample distributions (with equal or not equal variance) are statistically different.

${ }^{13}$ The Kolmogorov-Smirnov test is a non-parametric test for the null hypothesis that a random sample has been drawn from a specified theoretical (discrete or continuous) distribution. The test is used also to examine whether two samples come from the same distribution. It is sensitive to any type of difference in the two distributions - shape, location, etc.. The test is based on the largest difference between the two cumulative distributions.
} 
Table 3: Descriptive Statistics

\begin{tabular}{|l|l|l|r|r|r|r|r|r|}
\hline Variable & Sample & N & Mean & Median & Variance & $\begin{array}{l}\text { Coef. } \\
\text { Of Var. }\end{array}$ & $\begin{array}{l}\text { Skew- } \\
\text { ness }\end{array}$ & Kurtosis \\
\hline TOT-IN & Group & 1266 & 0.0326 & 0.014 & 0.004 & 198.002 & 7.960 & 90.160 \\
& Independent & 2430 & 0.029 & 0.014 & 0.002 & 174.364 & 6.258 & 56.350 \\
\hline PROD-IN & Group & 1266 & 0.023 & 0.009 & 0.003 & 216.501 & 8.024 & 97.436 \\
& Independent & 2430 & 0.018 & 0.008 & 0.001 & 191.025 & 7.390 & 89.317 \\
\hline PROC-IN & Group & 1266 & 0.009 & 0.003 & 0.001 & 263.384 & 10.042 & 138.695 \\
& Independent & 2430 & 0.011 & 0.003 & 0.001 & 272.678 & 8.416 & 93.2882 \\
\hline PROD- & Group & 1266 & 64.526 & 70 & 976.387 & 48.426 & -0.657 & -0.686 \\
REL-IN* & Independent & 2430 & 61.647 & 70 & 1055.748 & 52.707 & -0.502 & -0.881 \\
\hline PROC- & Group & 1266 & 35.474 & 30 & 976.387 & 88.085 & 0.657 & -0.686 \\
REL-IN & Independent & 2430 & 38.353 & 30 & 1055.748 & 84.7188 & 0.502 & -0.881 \\
\hline TOT-OUT & Group & 1266 & 55.043 & 60 & 1063.610 & 59.250 & -0.145 & -1.260 \\
& Independent & 2430 & 57.782 & 60 & 944.593 & 53.190 & -0.283 & -1.062 \\
\hline PROD- & Group & 1266 & 33.937 & 30 & 839.645 & 85.384 & 0.697 & -0.463 \\
OUT & Independent & 2430 & 35.040 & 30 & 776.875 & 79.544 & 0.593 & -0.490 \\
\hline PROC- & Group & 1266 & 21.107 & 10 & 671.052 & 122.732 & 1.598 & 2.012 \\
OUT & Independent & 2430 & 22.742 & 15 & 675.344 & 114.273 & 1.460 & 1.656 \\
\hline TOT-EFF & Group & 1266 & 113.552 & 29.323 & 176841.549 & 370.336 & 11.812 & 177.193 \\
& Independent & 2430 & 86.567 & 33.301 & 30413.887 & 201.458 & 6.256 & 61.919 \\
\hline PROD- & Group & 1177 & 109.919 & 23.848 & 229341.875 & 435.681 & 14.397 & 273.117 \\
EFF & Independent & 2192 & 90.348 & 27.624 & 143475.731 & 419.247 & 31.581 & 1260.148 \\
\hline PROC- & Group & 1003 & 160.508 & 42.654 & 209902.759 & 285.438 & 8.517 & 101.190 \\
EFF & Independent & 1894 & 157.129 & 43.766 & 232239.664 & 306.700 & 15.368 & 368.338 \\
\hline
\end{tabular}

* The variables complement to 100, therefore, as expected, the distributions of GROUP and

INDEP firms have complementary means, same variance, opposite Skweness and same Kurtosis.

R\&D budget in new products (processes) that independent firms. The difference between the means of the variable PROD-REL-IN (PROC-REL-IN) is statistically significant at the $1 \%$ level as well as the difference between the two entire empirical distributions. As Table 4 shows, the non parametric analysis gives support to Hypothesis I. 
In order to test whether firms involved in acquisitions invest a larger (smaller) share of their total $\mathrm{R} \& \mathrm{D}$ expenditures in new products (processes) than independent firms, holding other factors constant, we run an OLS regression with PROD-REL-IN and PROC-REL-IN as dependent variables. The independent variable in which we are interested is the group dummy (GROUP_DUM) ${ }^{14}$ that takes the value 1 if the firm belongs to a group, otherwise 0 . To control for size we include the log of firm total sales in 1992. Also, as a proxy for a possible extraction of R\&D from a foreign acquirer, we include a dummy which equals one if the headquarter of the group is outside of Italy, otherwise 0 . Furthermore, we control for industry effects by including 2- digit industrial (NACE) dummies.

Table 4: Two-sample tests for GROUP and INDEP firms

\begin{tabular}{|l|c|c|c|c|c|c|}
\hline & \multicolumn{2}{|c|}{ Levene's test } & \multicolumn{2}{c|}{ t-test for means } & \multicolumn{2}{c|}{$\begin{array}{c}\text { Kolmogorov-Smirnov } \\
\text { test }\end{array}$} \\
\hline & F & p-value & T & p-value & Z & p-value \\
\hline TOT-IN & $10.481^{* * *}$ & 0.001 & $-1.936^{*}$ & 0.053 & $1.310^{*}$ & 0.065 \\
\hline PROD-IN & $33.796^{* * *}$ & 0.000 & $-3.403^{* * *}$ & 0.001 & $1.492^{* *}$ & 0.023 \\
\hline PROC-IN & $4.610^{* *}$ & 0.032 & 1.445 & 0.149 & 0.563 & 0.909 \\
\hline PROD-REL-IN & $4.849^{* *}$ & 0.280 & $-2.622^{* * *}$ & 0.009 & $1.919^{* * *}$ & 0.001 \\
\hline PROC-REL-IN & $4.849^{* *}$ & 0.280 & $2.622^{* * *}$ & 0.009 & $1.919^{* * *}$ & 0.001 \\
\hline TOT-OUT & $15.701^{* * *}$ & 0.000 & $2.470^{* *}$ & 0.014 & $1.776^{* * *}$ & 0.004 \\
\hline PROD-OUT & $3.101 * *$ & 0.078 & 1.127 & 0.260 & $1.391 * *$ & 0.042 \\
\hline PROC-OUT & 0.297 & 0.585 & $1.817^{*}$ & 0.069 & $1.905^{* * *}$ & 0.001 \\
\hline TOT-EFF & $28.400^{* * *}$ & 0.000 & $-2.187^{* *}$ & 0.029 & $1.589^{* *}$ & 0.013 \\
\hline PROD-EFF & $6.602^{* * *}$ & 0.010 & -1.213 & 0.225 & $1.308^{*}$ & 0.065 \\
\hline PROC-EFF & 0.223 & 0.637 & -0.186 & 0.853 & 0.492 & 0.969 \\
\hline
\end{tabular}

*, **, *** denote statistical significance at the $0.1,0.05$, and 0.01 level respectively

\footnotetext{
${ }^{14}$ We use OLS estimators since we are interested in analysing partial correlations between the different dependent variables and the fact that firms are part of a group. We are not establishing any causal relation. Because of that, the possible endogeneity of our dependent variable (GROUP) is not anymore a problem.
} 
Table 5 shows that the qualitative results for the relation of investment in product versus process $\mathrm{R} \& \mathrm{D}$ are similar to the two sample test, though not significant. ${ }^{15}$ Nevertheless, the fact that the group dummy has a positive (negative) coefficient on relative product (process) R\&D rather supports than refutes the predictions of the model.

Similar but unreported OLS regressions on the relative output of product vs. process R\&D also support hypothesis I: firms in groups have a significantly ( $1 \%$ level) higher proportion of sales generated through product R\&D than through process $\mathrm{R} \& \mathrm{D} .{ }^{16}$ Thus, over and above the finding that hypothesis I can not be refuted, in combination with the results of table 3, we can even determine a moderate support.

Table 5: Regression results on investment variables

\begin{tabular}{|l|c|c|c|c|c|}
\cline { 2 - 6 } \multicolumn{1}{c|}{} & \multicolumn{2}{c|}{ Product R\&D } & \multicolumn{2}{c|}{ Process R\&D } & Aggr. R\&D \\
\cline { 2 - 6 } \multicolumn{1}{c|}{} & $\begin{array}{c}\text { PROD- } \\
\text { REL-IN }\end{array}$ & $\begin{array}{c}\text { PROD- } \\
\text { IN }\end{array}$ & $\begin{array}{c}\text { PROC- } \\
\text { REL-IN }\end{array}$ & $\begin{array}{c}\text { PROC- } \\
\text { IN }\end{array}$ & $\begin{array}{c}\text { TOT- } \\
\text { IN }\end{array}$ \\
\hline SIZE & $0.73^{*}$ & $-0.004^{* * *}$ & $-0.73^{*}$ & $-0.004^{* * *}$ & $-0.008^{* * *}$ \\
\hline & {$[1.65]$} & {$[-7.44]$} & {$[-1.65]$} & {$[-9.43]$} & {$[-10.24]$} \\
\hline GROUP_DUM & 1.49 & $0.01^{* * *}$ & -1.49 & $0.003^{* * *}$ & $0.014^{* * *}$ \\
\hline & {$[1.15]$} & {$[6.34]$} & {$[-1.15]$} & {$[2.89]$} & {$[6.07]$} \\
\hline HQ_DUM & 0.07 & -0.003 & -0.07 & 0.001 & -0.001 \\
\hline & {$[0.03]$} & {$[-1.0]$} & {$[-0.03]$} & {$[0.66]$} & {$[-0.39]$} \\
\hline IND_DUM & Mixed & Mixed & Mixed & mixed & mixed \\
\hline N & 3696 & 3696 & 3696 & 3696 & 3696 \\
\hline F & $18.33^{* * *}$ & $17.36^{* * *}$ & $18.33^{* * *}$ & $5.77 * * *$ & $14.02^{* * *}$ \\
\hline R2 (adj) & 0.1 & 0.1 & 0.1 & 0.03 & 0.08 \\
\hline
\end{tabular}

[t-values in brackets]

$*, * *, * * *$ denote statistical significance at the $0.1,0.05$, and 0.01 level respectively

a) the coefficients of some industrial sectors are significant at 0.1 , others at 0.05 and some others at 0.01 .

The analysis of the relative importance of product and process R\&D does not yet allow for conclusions about levels of R\&D investment. Firms in GROUP could invest a higher proportion of total R\&D in new products, but nevertheless invest a lower level than independent firms. We therefore test hypothesis II, which states that the level of product, process and aggregate

\footnotetext{
${ }^{15}$ It is worth noting that firm size has a positive impact on the proportion of product vs. process R\&D. We are exploring this issue in a separate paper.

${ }^{16}$ A direct inference in favour of the input-related hypothesis I either assumes no efficiency changes due to acquisitions, or that possible efficiency changes in product and process $R \& D$ are of equal magnitude.
} 
investment in R\&D will not be lower after acquisitions when compared to independent firms. This prediction is supported by the results. In fact, in line with our model, Table 3 shows that firms within a group invest $28 \%$ more in product R\&D (PROD-IN) and $13 \%$ more in aggregate R\&D (TOT-IN) than independent firms. These differences are statistically significant (at 0.01 level) as the tests in Table 4 show. With regard to the investment in new processes firms in group seems to invest less $(22 \%)$ than independent firms. However, the t-test and the Kolmogorov Smirnov test state that this difference is not significant. In other words, firms in group invest in process innovation as much as independent firms do.

When controlling for other factors, results in Table 5 change partially only for process innovation investment. In fact, holding others factors constant, the hypothesis II is fully supported: firms in group invest at a significantly higher level in product R\&D (PROD-IN), process R\&D (PRODIN), and in aggregate R\&D (TOT-IN) than independent firms.

\subsection{Effect of acquisitions on $R \& D$ performance and efficiency}

Before we turn to the analysis of R\&D efficiency we can first take a brief look at the influence of acquisitions on R\&D performance or output (please see the variables PROD-OUT, PROCOUT, and TOT-OUT ). Interestingly, the tendency to invest more (less) in product (process) $\mathrm{R} \& \mathrm{D}$ in acquisitions, which we observed in tables 3 and 4 , is not equivalently reflected in the performance of product (process) R\&D. Table 3 and 4 show that independent firms have higher percentage of total sales realized with new products and processes. The differences in the means and in the entire distributions are statistically significant with the exception of the mean of the percentage of total sales realized with new products. However, holding other factors, the OLS coefficients in table 6 show that belonging to a group does not explain the different percentage of 
total sales due to innovation. The higher levels of total $R \& D$ investment in acquisitions do not seem to have a dominant impact since none of the respective coefficients of GROUP_DUM are statistically significant.

Table 6: Regression results on performance and efficiency variables

\begin{tabular}{|l|c|c|c|c|c|c|}
\cline { 2 - 7 } \multicolumn{1}{c|}{} & \multicolumn{2}{c|}{ Product R\&D } & \multicolumn{2}{c|}{ Process R\&D } & \multicolumn{2}{c|}{ Aggregate R\&D } \\
\cline { 2 - 7 } \multicolumn{1}{c|}{} & $\begin{array}{c}\text { PROD- } \\
\text { OUT }\end{array}$ & $\begin{array}{c}\text { PROD- } \\
\text { EFF }\end{array}$ & $\begin{array}{c}\text { PROC- } \\
\text { OUT }\end{array}$ & $\begin{array}{c}\text { PROC- } \\
\text { EFF }\end{array}$ & $\begin{array}{c}\text { TOT- } \\
\text { OUT }\end{array}$ & $\begin{array}{c}\text { TOT- } \\
\text { EFF }\end{array}$ \\
\hline SIZE & $-0.68^{*}$ & $0.38^{* * *}$ & -0.5 & $0.44 * * *$ & $-1.19^{* * *}$ & $0.36^{* * *}$ \\
\hline & {$[-1.71]$} & {$[6.13]$} & {$[-1.35]$} & {$[5.78]$} & {$[-2.62]$} & {$[9.12]$} \\
\hline GROUP_DUM & 1.22 & $-0.32^{*}$ & -0.35 & $-0.67 * * *$ & 0.88 & $-0.25^{* *}$ \\
\hline & {$[1.05]$} & {$[-1.77]$} & {$[-0.32]$} & {$[-2.99]$} & {$[-0.66]$} & {$[-2.18]$} \\
\hline HQ_DUM & $-3.21^{*}$ & 0.24 & -0.08 & $0.80^{* *}$ & -3.30 & 0.16 \\
\hline & {$[-1.74]$} & {$[0.82]$} & {$[-0.05]$} & {$[2.19]$} & {$[-1.57]$} & {$[0.86]$} \\
\hline IND_DUM & mixed & mixed & Mixed & mixed & mixed & mixed \\
\hline N & 3696 & 3696 & 3696 & 3696 & 3696 & 3696 \\
\hline F & $13.02^{* * *}$ & $32.65^{* * *}$ & $6.73^{* * *}$ & $2.2^{* * *}$ & $5.62^{* * *}$ & $26.96^{* * *}$ \\
\hline R2 (adj) & 0.07 & 0.17 & 0.04 & 0.01 & 0.03 & 0.14 \\
\hline
\end{tabular}

[t-values in brackets]; all coefficients in the efficiency regressions are divided by $10^{2}$

$*$, **, *** denote statistical significance at the $0.1,0.05$, and 0.01 level respectively

a) the coefficients of some industrial sectors are significant at 0.1 , others at 0.05 and some others at 0.01 .

Consequently, when we consider the results of product, process and aggregate R\&D efficiency, there is clear evidence that dynamic efficiency decreases with acquisitions. All three efficiency dependents (PROD-EFF, PROC-EFF, and TOT-EFF), which divide R\&D output through input, are adversely influenced by acquisitions (negative GROUP-DUM coefficients). These results suggest that firms involved in acquisitions have, ceteribus paribus, a lower efficiency in $\mathrm{R} \& \mathrm{D}$ than independent firms, thus supporting hypothesis IIIb.

Since our regressions control for size as well as industry effects, it is unlikely that these inefficiencies are caused by diseconomies of scale. As we will argue in the conclusion, it is also not likely that these inefficiencies are purely driven through market externalities, so that we have to assume that the decrease in dynamic efficiencies is primarily due to firm specific post-merger integration problems. 


\section{Concluding Remarks}

Based on a theoretical model this paper argues that market externalities can explain differences in firms’ propensity to invest in product and process R\&D before and after acquisitions. Specifically, the model predicts that acquisitions lead to a higher relative investment in product versus process $R \& D$, while the absolute level of total $R \& D$ investment will not be lower than that of independent firms. The empirical analysis supports both theoretical predictions. In addition, the empirical results show that firms after acquisitions have, despite higher total R\&D investment, a lower R\&D efficiency than independently competing firms.

While our model provides a clear argumentation for an optimal R\&D portfolio and level of investment, the reported negative effect on dynamic efficiency can only be explained indirectly: Following concepts in industrial dynamics the magnitude of marginal returns to product and process innovation are likely to change through the life cycle of a technology (e.g. Abernathy and Utterback, 1982). It can be argued that, especially in the beginning of a technological life cycle, marginal returns to innovation are so high that the incentive to expand generally overcompensates the opposing incentive to reduce absolute investment in process innovation, which an acquisition creates through the internalisation of negative externalities. Following this line of argument, exactly the opposite could be hypothesised for a very mature or even declining phase of a technological life cycle, in which marginal returns to innovation (product as well as process) are significantly lower. Between these two extremes there is also a stage of moderate marginal returns to innovations in the technological life cycle. Here, the relative and level effects of product and process R\&D should be aligned. The fact that this is only partially supported by our results can have two explanations: from an industrial dynamics' view it may be argued that our data of the Italian manufacturing industry have a bias towards more mature technologies, which generally reduces incentives to invest in R\&D. However, this would not completely explain our finding of increasing investment in product $\mathrm{R} \& \mathrm{D}$. Thus, with regard to dynamic efficiency, we 
take on a firm's perspective. In fact, our empirical results suggest that acquisitions lead to postmerger integration problems, which over-compensate potential efficiency gains in product and process $\mathrm{R} \& \mathrm{D}$. 


\section{Bibliography}

Abernathy, W.J. and J.M. Utterback, 1979, Patterns of Industrial Innovation, Technology Review, 80, $41-47$.

Abernathy, W.J. and J.M. Utterback, 1982, Patterns of Industrial Innovation, in Tushman, M.L. and Moore, W.L. (eds.), Readings in the management of innovation, Pitman, Boston, 97-108.

Adams, J.D. and M. Marcu, 2004, R\&D sourcing, joint ventures and innovation: a multiple indicators approach, NBER, 10474.

Agarwal R. and D.B. Audretsch, 2001, Does entry Size Matter? The Impact of the Life Cycle and Technology on Firm Survival, The Journal of Industrial Economics, 1, 21-43.

Ahuja G. and R. Katila, 2001, Technological acquisitions and the innovation performance of acquiring firms: A longitudinal study, Strategic Management Journal, 22, 197-220.

Anderson, P. and M. Tushman, 1990, Technological discontinuities and dominant designs: A cyclical model of technological change, Administrative Science Quarterly, 35, 604-633.

Blonigen, B. and C. Taylor, 2000, R\&D activity and acquisitions in High Technology Industries: evidence from the US Electronics Industry, Journal of Industrial Economics, 47, 1, 47-71.

Bonnano, G. and B. Haworth, 1998, Intensity of competition and the choice between product and process innovation, International Journal of Industrial Organization, 16, 495-510.

Cassiman, B., Colombo, M., Garrone, P. and R. Veugelers, 2003, The impact of M\&A on the R\&D process. An empirical analysis of the role of technological and market relatedness, mimeo.

Cassiman, B., and R. Veugelers, 2002, R\&D cooperation and spillovers: some empirical evidence from Belgium, American Economic Review, 92(4), 1169-84.

Cohen, W. and R. Levin, 1989, Empirical Studies of Innovation and Market Structure, in Schmalensee R; and R. Willig (Eds.) Handbook of Industrial Organisation, North-Holland, chapter 18, 1060-1107.

D’Aspremont, C. and A. Jacquemin, 1988, Cooperative and noncooperative R\&D in duoploy with spillovers. American Economic Review, 78, 1133-1137.

De Bondt, R., 1996, Spillovers and innovative activities, International Journal of Industrial Organisation, 15, 1-28.

De Bondt, R. and R. Veugelers, R., 1991, Strategic investment with spillovers, European Journal of Political Economy, 7, 345-366.

Duranton, G., 2000, Cumulative Investment and Spillovers in the Formation of Technological Landscapes, The Journal of Industrial Economics, 2, 205-213. 
Eswaran, M. and N. Gallini, 1996, Patent policy and the direction of technological change, RAND Journal of Economics, 27, 722-746.

EUROSTAT, 2003, Meeting of the Working Party on Science, Technology and Innovation (STI) Statisticse, Luxembourg.

Gugler, P. and R. Siebert, 2004, Market power versus efficiency effects of mergers and research joint ventures: evidence from the semiconductor industry, NBER Working Paper 10323

Hall, B. 1990, The Impact of Corporate Restructuring on Industrial Research and Development, Brookings Papers on Economic Activity.

Hall, B. 1999, Mergers and R\&D revisited, mimeo.

Hitt, M.A., R.E. Hoskisson, R.D. Ireland and J.S. Harrison, 1991. 'Effects of acquisitions on R\&D inputs and outputs', Academy of Management Journal, 34(3), 693-706.

Hitt, M., R. Hoskisson, R. Johnson and D. Moesel, 1996, The Market for Corporate Control and Firm Innovation, Academy of Management Journal, 39, 1084-1119.

Katz, M.L. and H.A. Shelanski, 2004, Merger Policy and Innovation: Must Enforcement Change to Account for Technological Change?, NBER Working Paper 10710

Kleinknecht, A., K. van Montfort and E. Brouwer, 2002, The non-trivial choice between innovation indicators, Economic Journal of Innovation and New Technology, 11, 2, 109-121.

Kleinknecht, A. (Ed.), 1996, Determinants of Innovation: The Message from New Indicators. Macmillan, London.

Klepper, S., 1996, Entry, exit, and innovation over the product life-cycle, American Economic Review, 86, 562-583.

Klepper, S. and E. Graddy, 1990, The evolution of new industries and the determinants of market structure, RAND Journal of Economics, 2.

Mairesse, J., Mohnen, P., 2002, Accounting for innovation and measuring innovativeness: an illustrative framework and an application, American Economic Review, 92, 226-231.

Miller, D. and P. Friesen, 1986a, Porter's (1980) Generic Strategies and Performance: An Empirical Examination with American Data. Part I: Testing Porter, Organization Studies, 1986a, 7, 37-56.

Miller, D. and P. Friesen, 1986b, Porter's (1980) Generic Strategies and Performance. Part II: Performance Implications, Organization Studies, 1986b, 7, 255-261.

OECD, 1997, Proposed guidelines for collecting and interpreting technological innovation data: the "Oslo" Manual. Organisation for Economic Development and Co-operation, Paris.

Porter, M.E., 1980, Competitive Strategy, 1980, The Free Press, New York. 
Ravenscraft D.J. and F. M. Scherer, 1987. Mergers, sell-offs, and economic efficiency. The Brookings Institution, Washington DC, US.

Röller, L-H, Stennek, J \& F. Verboven, 2001, Efficiency gains from mergers, European Economy, 5.

Rosenkranz, S., 2003, Simultaneous Choice of Process and Product Innovation when Consumers have a Preference for Product Variety, Journal of Economic Behavior \& Organization 50, 2003, 183-201.

Scherer, F. M., 1992, Schumpeter and plausible capitalism, Journal of Economic Literature, 30.

Suarez, F. and Utterback, J. 1991, Dominant designs and the survival of firms, Sloan School of Management, MIT, Working Paper, 42-91.

Tushman, M. and P. Anderson, 1986, Technological discontinuities and organization environments, Administrative Science Quarterly, 31, 439-465.

Yin, X. and E. Zuscovitch, 1998, Is firm size conducive to R\&D choice? A strategic analysis of product and process innovations, Journal of Economic Behavior and Organization, 35, 243-262. 